\title{
JEAN-PIERRE DUPREY ET LA COULEUR NOIRE*
}

\author{
Jean-Michel Goutier
}

RESUMO: Após exemplificar sua afirmação inicial de que a cor preta ocupa um lugar central no surrealismo, o autor concentra sua exposição na vida e nos escritos do poeta e artista plástico Jean-Pierre Duprey, que tem a cor preta como marca predominante de seu fazer artístico, comparando-o com alguns outros poetas que foram assumidamente surrealistas ou apenas "marcados" pelo surrealismo.

PALAVRAS-CHAVE: Duprey (J.-P.), surrealismo, surrealistas, poesia, cor preta. $^{* *}$

Vincent Van Gogh comptait trente-sept gris. Combien de noirs pour Jean-Pierre Duprey ${ }^{1}$ ? Sans omettre celui des "adroits tireurs qui visent juste et mettent toujours dans le noir — dans le noir de la nature humaine" (NIETZSCHE).

À propos de Jacques Rigaut ${ }^{2}$ je me souviens avoir affirmé, au cours d'un débat, qu'il était, parmi les personnages les plus noirs qui traversèrent

\footnotetext{
* Conferência proferida na Facultà di lingue e letterature straniere de Bari, Itália, em 27 de abril de 1993.

Jean-Michel Goutier é poeta e ensaísta, foi membro do movimento surrealista de 1956 até 1969.

** O resumo e as palavras-chave foram traduzidos do francês por Robert Ponge.

${ }^{1}$ DUPREY, Jean-Pierre [Rouen, 1930 - Paris, 1959]. "Le 'Prince du royaume des doubles' comme le qualifiait Breton dans sa notice de l'Anthologie de l'humour noir où un extrait de La Forêt sacrilège clôt l'édition définitive. Fasciné très jeune par la lecture de Rimbaud, Jarry et Artaud, il confie ses premiers poèmes, il avait seize ans, à Jacques Brenner qui en retient quatre pour sa revue Seine. Deux ans plus tard il expédie le manuscrit de Derrière son double à la galerie La Dragonne, où Breton le découvre. [...]. Publier, en 1950, le texte d'un inconnu de vingt ans n'était pas chose fréquente et c'est ainsi que naissent les légendes. Duprey demeurera à jamais le double de cet astre calciné, figure de proue des éditions qui l'ont publié pour la première fois. Politessę des poètes: le dernier signe de Duprey sur cette terre est d'adresser à Breton, avant de 's'ensevelir dans l'air', son ultime manuscrit: La Fin et la manière" (GOUTIER. Notice sur J.-P. Duprey. Publiée in Le Soleil Noir; recherches, découvertes, trajectoires. Catalogue de l'exposition tenue au Musée d'Art Moderne - "Carré d'Art" - de Nîmes du 07.05 au 28.08.1993. Nîmes, Carré d'Art, 1993).

${ }^{2}$ RIGAUT, Jacques [Paris, 1898 - Châtenay-Malabry (Hauts-de-Seine), 1929]. "Je serai sérieux comme le plaisir" (Papiers posthumes, 1934).
} 
la nuit d'orage des débuts du surréalisme, un véritable héros de roman noir dans la lumière du Melmoth de Charles Robert Maturin. Le noir a une grande résonance dans le surréalisme. Il y a l'humour noir selon Breton, où l'humour s'affirme comme révolte supérieure de l'esprit, l'exaltation du roman frénétique ou roman noir, la célébration de Xavier Forneret ${ }^{3}$, "l'Homme noir", mais aussi dans la période surréaliste d'après la Seconde Guerre mondiale la "génération noire" (JOUFFROY) ${ }^{4}$, constellation de poètes qui comprend notamment Jean-Pierre Duprey et Stanislas Rodanski ${ }^{5}$. Les éditions du Soleil Noir, que je représente ici, ont publié les æeuvres complètes de ces deux poètes. La raison sociale de ces éditions, je dirais plutôt la raison mentale, a été emprutée à l'ouvrage d'Eliphas Lévi, La Clef des grands mystères: "Le téméraire qui ose regarder le soleil sans ombre devient aveugle et alors pour lui le soleil est noir"

La couleur noire occupe une place centrale dans la poésie de Duprey. Il s'agit de ce "noir plus noir que le noir" où, d'après Eugène Canseliet, se développe la pierre philosophale (CANSELIET) ${ }^{7}$. Sans recensement systématique du vocable noir dans les CEuvres complètes, dès les premiers poèmes le noir est mis. II est omniprésent dans "la nuit prise comme profondeur" de Derrière son double (DUPREY), dans les extraits de "L'Ombre sagittaire" publiés dans La Révolte en question où, comme "un couloir sans bruit qui coule dans lui-même", il évoque de manière irrépressible le couloir qui conduit de la cellule du condanné à mort à la guillotine ${ }^{8}$. Dans La Fin et la manière, les poèmes "Santé noire" et "L'Éternité dans les draps noirs" comptent parmi les "réussites" les plus désespérées du poète. Enfin Ueline la Noire et son double la Sorcière ou Extervitreuse le personnage Noir mènent le bal dans La Forêt sacrilège (DUPREY).

C'est Jorge Luis Borges qui disait que le poète invente ses précurseurs. Avec ceux de Duprey il faut se livrer au jeu des correspondances:

Chez Rimbaud dans Une Saison en enfer: "Enfin, ô bonheur, ô saison, j'écartai du ciel l'azur, qui est du noir, et je viens, étincelle d'or de la

${ }^{3}$ FORNERET, Xavier [Beaune (Côte d'Or), 1809-1884]. Poète romantique français redécouver par les surréalistes. Auteur de Le Diamant de l'herbe, republié par Éric Losfeld en 1955.

${ }^{4}$ pÉ les surréalistes. Auteur de Le DiamoT, Bernard. Les Écrits. Avec, en préface, "Lettre noire" d'Alain Jouffroy. Bruxelles,

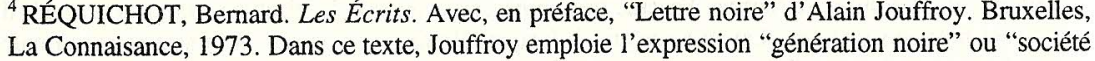
secrète de l'écriture".

${ }^{5}$ RODANSKI, Stanislas [Lyon, 1927-1981]. Poète. Surréaliste dans la solitude avant de devenir surréaliste dans le silence. "La mort est une distraction passagère".

${ }^{6}$ LÉVI, Eliphas (de son véritable nom CONSTANT, Alphonse Louis) [Paris, 1810-1875]. Après avoir été tenté par le séminaire il se tourne vers l'ocultisme. Il influence la pensée de Victor Hugo et André Breton le cite souvent, notamment dans L'Art magique.

${ }^{7}$ CANSELIET, Eugène. Auteur de L'Alchimie expliquée sur ses textes classiques. (Paris, édit. Pauvert, 1980)

${ }^{8}$ La Révolte en question, Le Soleil Noir positions, n. 1, Paris, Février 1952. - Le Temps des

assassins, Le Soleil Noir positions, n. 2, Paris, Juin 1952 lumière nature". Plus on s'approche de l'azur plus il devient noir constatent les scientifiques après les poètes (DAGEN).

Chez Artaud dans Coleridge le traître: "Mon âme (aujourd'hui je n'en ai plus et je ne crois plus que cela existe) est toujours allée au noir." En 1946, à seize ans, Duprey écrivait déjà: "Le noir a pétrifié le noir de mon âme, le noir de mon sang, la chair de ma douleur; la boue m'a racheté sans la lumière et le noir a jailli pour détacher la boue" (DUPREY).

Chez Jarry dans César-Antéchrist:

On oppose le Néant à l'Être, puis par l'erreur croissant en mode d'avalanche, le Néant à la vie. Voici les contraires: le Non-Être et L'Être, bras de fléau du Néant pivot: 1'Être et la Vie ou la Vie et la Mort. Le soleil noir subsiste après les soleils tous les jours redorés du ciel terrestre.

Le 18 janvier 1949, André Breton notait, dans le cahier de permanence de la Dragonne, librairie-galerie qui accueillait les surréalistes: J'ai pris connaissance hier, à la Dragonne, d'un envoi de JeanPierre Duprey adressé à la "Revue" Solution surréaliste. Envoi des plus remarquables du point de vue poétique notamment (pouvant tout au plus s'apparenter à certains textes de Jarry). Écrit ce matin à Duprey pour le féliciter et demander à le voir. ${ }^{9}$

Le lien qui unit Duprey aux poètes du Grand Jeu ${ }^{10}$, René Daumal et Roger Gilbert-Lecomte, "nier tout et ne plus concevoir que l'abîme" (GILBERT-LECOMTE, 1977), est le Nerval d'Aurélia dont la dernière lettre se termine par "Ne m'attends pas ce soir, car la nuit sera noire et blanche" (NERVAL). Ceux qui affrontèrent "la Noire Idole", nom que donnait Thomas de Quincey à sa carafe de laudanum et que Laurent Tailhade prit pour titre d'une étude sur la morphinomanie ${ }^{11}$, partagent avec l'auteur de Derrière son double nombre de visions semblables.

Le fragment du poème "La Sainte-Enfance ou suppression de la naissance" de Gilbert-Lecomte:

Je parlerai du noir

À l'envers des miroirs

Je parlerai du noir

De l'immortel tourment

Du plus vieux désespoir

Devant le monde absent

Alors qu'il fera blanc. (GILBERT-LECOMTE, 1955)

est à rapprocher des "nuits" de La Fin et la manière:

Et le blanc disait: je suis lucide.

Le noir disait: je suis tout.

${ }^{9}$ BRETON, André. Fragment inédit.

${ }^{10}$ Le Grand Jeu: Revue créee par René Daumal, Roger Gilbert-Lecomte et quelques autres. Trois numéros parus: juin 1928, mai 1929, octobre 1930. Groupe du même nom marqué par le surréalisme mais résolument en marge de celui-ci.

TAILHADE, Laurent [Tarbes, 1854 - Combs-la-ville, 1919]. Poète et pamphlétaire. Auteur de la "Ballade Solness": "Anarchie! Ô porteuse de flambeaux." 
Le blanc était la pensée tremblante de la nuit.

Le noir pensait: je suis le bout. (DUPREY)

Forgeur de langage, sculpteur d'ombres acérées, capteur, à l'instar d'Artaud, des nouvelles révélations de l'être, Duprey choisit les noirs pour une partie contre lui-même. Le titre "La potence du gouffre...", retenu par Paule Thévenin pour désigner un dessin d'Aurtaud de 1945, correspond au premier mot de la phrase écartelée sur la page même où se trouve le dessin: "La potence du gouffre/ est l'être et non/ son âme/ et c'est son corps" (ARTAUD, 1986). Phrase qui renvoie, chez Duprey, à La Forêt sacrilège (Acte II, Scène 3): "Estern - L'Aigle se foudre et la chasse lointaine est commencée de même qu'une chute sans fin au fond d'un gouffre DONT LE FOND n'est qu'en nous!..." (DUPREY).

Duprey et Rodanski ont connu les horreurs de la Seconde Guerre mondiale. En 1944, Rodanski est déporté à Mannheim où il fut interné dans un camp de travail; il avait dix-sept ans. Après le terrible bombardement de Rouen, le 19 avril 1944, Duprey (il avait, lui, quatorze ans) participe, avec les autres élèves de sa classe, aux opérations de sauvetage. Il inscrit alors dans ses carnets qu'il était épuisé le soir d'avoir "passé la journée à refaire des morts entiers avec des morceaux pour pouvoir les enterrer" (DI DIO). Pour la génération de Breton, Aragon, Péret, la Grande Guerre fut la vérification par l'absurde de la consternante stupidité des valeurs régissant la société; pour les adolescents de la "génération noire", le second conflit mondial fut, avec ses perversions idéologiques, nazisme et stalinisme, plus pernicieux encore. Dans le premier numéro de la revue Néon, en 1948, Rodanski écrit:

C'est une main de cendre qui fait le dernier signe au tableau de l'évidence noire où tant de scribes s'inscrivent en faux que l'on ne saurait plus distinguer qu'un brouillon du monde qui pourtant suit son cours dans toutes les mains - qu'elles soient ouvertes ou fermées. (RODANSKI)

L'édition définitive de l'Anthologie de l'humour noir de Breton se termine, comme celle de 1950, sur la notice dédiée à Jean-Pierre Duprey: "Il ne dépend ni de lui ni de moi que dans la composition de l'humour noir, aujourd'hui par rapport il y a dix ans, il faille forcer la dose de noir pur" (BRETON)

Pour la jeunesse éprise d'une liberté longtemps attendue, les années cinquante s'ouvrent sur des menaces de guerre atomique. Aux craquements des banquises de la Guerre froide s'ajoute en 1954 la gangrène de la "pacification" en Algérie. Duprey, disparu en 1959, et Breton, en 1966, ne connaîtront malheureusement pas les "appels d'air" libertaires de Mai 1968.
À l'aube du surréalisme, Jacques Rigaut, Jacques Vaché $^{12}$ et Arthur Cravan $^{13}$, ces trois "suicidés de la société"14 ont fasciné leurs contemporains; pour certains de ceux, dont je suis, qui ont eu vingt ans a la mi-temps du siècle, leurs héritiers - Duprey, Rodanski, Paalen ${ }^{15}$, Réquichot $^{16}$ - demeurent avant tout des anti-pères, des anti-maîtres à penser, des anti-modèles. Ces déserteurs de la littérature, de l'art et de la vie fournissent des armes aux terrorristes de l'esprit que sont les véritables poétes, qu'ils écrivent ou qu'ils n'écrivent pas.

À flanc d'abîme Duprey passe conduisant d'une main sûre sa vie et sa mort, cette paire de loups.

\section{BIBLIOGRAPHIE}

ARTAUD, Antonin. Coleridge le traître. Revue K. Numéro double, 1-2. Juin 1948.

ARTAUD, Antonin. Dessins et portraits. Éd. établie, présentée et annotée par Paule Thévenin, avec un essai de Jacques Derrida. Paris, Gallimard, 1986.

BRETON, André. Anthologie de l'humour noir. 1939. Éd. revue et définitive: Paris, Pauvert, 1966.

DAGEN, Philippe. Article sur "L'Azur", Exposition à la Fondation Cartier, Jouy-en-Josas, 1993. Le Monde. 27 août 1993.

DI DIO, François. Biographie de J.-P. Duprey. In: DUPREY. Euvres complètes. Paris, Christian Bourgeois, 1990

DUPREY, Jean-Pierre. CEuvres complètes. Paris, Christian Bourgeois, 1990.

GILBERT-LECOMTE, Roger. La Dialectique de la révolte. Le Grand Jeu, épreuves du n. 4. Réimpression: Paris, Jean-Michel Place, 1977.

GILBERT-LECOMTE, Roger. Testament. Paris, Gallimard, 1955. (Coll. Métamorphoses).

${ }^{12}$ VACHÉ, Jacques. [Lorient, 1895 - Nantes, 1919]. Un maître incontesté de l'insoumission surréaliste. Auteur des Lettres de guerre (1920). Inventeur de l'humour (sans h) explosif et

dévastateur.

${ }^{19}$ CRAVAN, Arthur. (Fabian Lloyd, dit). [Lausanne, 1887 - Golfe du Mexique, 1920]. Poète et boxeur. Éditeur et unique rédacteur de la revue Maintenant qui préfigure l'aventure Dada.

${ }_{15}^{14} \mathrm{Du}$ titre de l'essai d'Artaud: Van Gogh, le suicidé de la société, 1947.

${ }^{15}$ PAALEN, Wolfgang [Vienne, 1905 - México, 1959]. Peintre et écrivain. Inventeur de la tecnique du "fumage". Organisateur en 1940, à México, avec le poète César Moro, d'une exposition internacionale du surréalisme. Fondateur de la revue Dyn (1940-1944).

${ }^{16}$ RÉQUICHOT, Bernard [Asnières-sur-Vègre (Sarthe), 1929 - Paris, 1961]. Peintre et poète. “[...]. Ne sais-tu donc pas qu'un poète, qu'un artiste, qu'un peintre, qu'un révolutionnaire digne de ce nom doit être individualiste, et dans le monde moderne plus que jamais" (Lettre à Jean Criton, 14.01.1952). 
JOUFFROY, Alain. Lettre noire, préface à: RÉQUICHOT, Bernard. Les Écrits. Bruxelles, La Connaissance, 1973.

NERVAL, Gérard de. Lettre à Mme Labrunie, 24 janvier 1855. In: CEuvres. Paris, Gallimard, t.1. (Bibliothèque de la Pléiade). Correspondance n. 359.

NIETZSCHE, Friedrich. Humain: trop humain. In: Humain trop humain et Fragments posthumes (1876-1879). Paris, Gallimard, 1968.

RODANSKI, Stanislas. Des Proies aux chimères. Paris, Plasma, 1983. (Coll. En dehors). 